\title{
TREND IN NATURAL ILLUMINANCE LEVELS BY MANN- KENDALL METHOD IN CHONGQING, CHINA
}

\author{
QUAN, L. $^{1}-\mathrm{HE}, \mathrm{Y}^{2^{*}}-$ ZHANG, $\mathrm{X}^{2}$ \\ ${ }^{1}$ Faculty of Chongqing Jianzhu College, 400039 Chongqing, China \\ (e-mail:65771923@qq.com; phone: +86-133-2020-5120) \\ ${ }^{2}$ Faculty of Architecture and Urban Planning, Chongqing University \\ 400045 Chongqing, China \\ (e-mail:543346273@qq.com-X. Zhang;phone:+86-133-2026-9588) \\ *Corresponding author \\ e-mail:he_ying@cqu.edu.cn \\ (Received $1^{\text {st }}$ Jul 2018; accepted $13^{\text {th }}$ Sep 2018)
}

\begin{abstract}
Changes in the trend of the total natural light illumination value in Chongqing, China was studied based on solar irradiance data of Chongqing from 1961 to 2010. The overall and inter-annual change trends of annual and monthly total natural light illuminance values were analyzed by Mann-Kendall method, meanwhile the luminous efficacy model was integrated in the analysis of data. The result showed that the basic trend in the change of total illuminance value is due to the reduction of natural light intensity. The change in trend was very obvious, and the alteration occurred in 1974. Monthly total illuminance values in Chongqing had no changed trend in May, in September, in November, a very obvious decreasing trend occurred in January, in July, in August and in December, an obvious trend occurred in February, in April and in October, and a not obvious one in March. At the same time, the annual variation of the total monthly illuminance of natural light fluctuates little in January, in February, in October, in November, and in December, and fluctuates widely in March, in April, in May, in June, in July, in August, and in September. The lowest monthly total illuminance values were observed in January and December, and the highest monthly illuminance values were observed in July and in August. The total natural light illuminance has the highest value in summer, and the lowest value in winter, and a moderate value in spring and in autumn.
\end{abstract}

Keywords: solar radiation, luminous efficacy, natural light illuminance, Mann-Kendall method

\section{Introduction}

With shortages of energy resources, it is of great significance to make full use of natural light and pursue ecological and sustainable development. Daylighting climate data are the basis for the application of natural light in buildings; illuminance data are one of the core contents of daylighting climate data. China has obtained illuminance data in a study from 14 cities through two consecutive years of observation of natural light (1983 to 1984) in typical Chinese daylighting climate regions (Wu, 1987a). China was divided into five daylighting climate zones according to natural light distribution and designed daylighting design standards (Wu, 1987a). The International Daylighting Measurement Program (IDMP) was implemented in 1991 to acquire daylighting climate observation data from some cities (including Beijing and Chongqing in China) throughout the world (He et al., 2012). After that, the relevant daylighting climate observation work is basically in a state of stagnation.

As the visible part of solar irradiance, natural light has a close relationship with solar irradiance. Data on solar irradiance are abundant owing to the regular observation project of the meteorological department. Therefore, natural illuminance data can be obtained through solar irradiance. However, luminous efficacy is the key factor in obtaining 
illuminance data from solar irradiance. Luminous efficacy is the ratio of natural illuminance to solar irradiance. Several authors have suggested models to derive the luminous efficacy for different sky condition. Littlefair model, Perez model (Perez et al., 1990), Olseth \& Skartveit model, Chung model and Munerer \& Kinghorn model (Muneer and Gul, 1998). The starting points and the model structures of these model calculations are different, and the accuracy of different models in different countries and regions is also different (Luo et al., 2011; Wang et al., 2011). Wu (1987a) proposed a monthly and annual luminous efficacy calculation model by combining China's daylighting climate observation data to meet the requirements of daylighting chimate zones and daylighting design. Solar irradiance values throughout the world have changed greatly in recent years as a result of the changing global climate (Zhang et al., 2011), worsening atmospheric pollution (Streets et al., 2008; Wand et al., 2012), and rapid urbanization process (Alpert et al., 2005). Consequently, natural illuminance has also changed (Shen et al., 2008). However, only very few relevant reports examine the changing characteristics and trends of natural illuminance. Since the total illuminance values of natural light varies greatly from year to year, missing values and outliers may occur, the accuracy of ordinary linear regression methods will be affected. The non-parametric test method (Mann-Kendall test method; Kendall, 1975) can reveal the trend of the time series well. It does not require the sample to follow a certain distribution, nor is it subject to a few abnormal values, and does not require statistical analysis. It is suitable for non-normally distributed data and it has been widely used in meteorological research (McBean and Motiee, 2008; Hamed, 2009; Shen, 2010), but it has not applied to analyze the changing natural light illuminance so far. For this reason, in this paper, the Mann-Kendall test method and statistical methods are used to analyze the variation trend of natural light illumination in Chongqing, China.

Chongqing is located in western China, lacking natural light resources, and the use of natural light is particularly important. Therefore, it is necessary to study the natural illuminance of Chongqing to obtain the natural light trend in Chongqing over the years, and then accurately assess the natural light environment in Chongqing. It will provide basic data for the use of natural light, and guide the design and application of natural light.

\section{Data and methods}

Although Chongqing has accumulated some annual light climate observation data, more long-term and large-scale light climate observation data are required to understand the changes in Chongqing's daylighting climate. Therefore, it is necessary to use rich irradiance data to obtain illuminance data.

\section{Luminous efficacy model}

Irradiance data can be obtained from meteorological observatories, so luminous efficacy $\mathrm{K}$ is the key factor in obtaining data on outdoor natural illuminance value. As far as we know (Wu, 1987a; Wang et al., 2011), there are many luminous efficacy models at present. Different models have different model parameters, and their accuracy varies from region to region. How to choose a conversion model suitable for Chongqing is the key to accurately obtain the natural illuminance value. The monthly and annual luminous efficacy model proposed by Wu et al. (1987a) has a relatively high accuracy. Its relevant parameters can be obtained from meteorological observation data suitable for determining daylighting climate characteristics. Therefore, we choose this model as the luminous 
efficacy model. This model was utilized in the present study to obtain natural illuminance values in China. The model considers four factors as parameters. These factors are geographic latitude, altitude, vapor pressure, and sunshine duration. A quaternary simple linear regression equation $(E q .1)$ was established in this study by integrating annual $\mathrm{K}$ values:

$$
K_{\mathrm{G} i}=B_{i}+C_{i} N+D_{i} H+E_{i} \mathrm{e}+F_{i} S
$$

In the equation, $i$ is year or month; $K_{G}$ is the value of annual or monthly luminous efficacy $\left(\mathrm{lx} / \mathrm{w} \cdot \mathrm{m}^{-2}\right) ; N$ is geographic latitude $\left(^{\circ}\right) ; H$ is altitude $(\mathrm{m})$; e is annual or monthly vapor pressure $(\mathrm{hPa}) ; S$ is monthly for the whole year or monthly average sunshine duration (h); $B_{i}, C_{i}, D_{i}, E_{i}, F_{i}$ are equation regression coefficients. The regression coefficients of the equations for the whole year and each month in Equation 1 can be found in the Table 1 (Wu, 1987a).

Table 1. Annual and monthly $K_{G}$ value equation regression coefficients

\begin{tabular}{c|c|c|c|c|c}
\hline Coefficient & $\boldsymbol{B}_{\boldsymbol{i}}$ & $\boldsymbol{C}_{\boldsymbol{i}}$ & $\boldsymbol{D}_{\boldsymbol{i}}$ & $\boldsymbol{E}_{\boldsymbol{i}}$ & $\boldsymbol{F}_{\boldsymbol{i}}$ \\
\hline Jan & 205.5471 & -1.7685 & -0.0044 & -4.8330 & -0.1077 \\
Feb & 152.6140 & -1.2209 & -0.0028 & -0.0384 & 0.0188 \\
Mar & 204.6445 & -1.6917 & -0.0053 & -3.0371 & -0.0590 \\
Apr & 198.8032 & -1.7017 & -0.0042 & -1.6187 & -0.0388 \\
May & 318.8958 & -3.1121 & -0.0180 & -4.4467 & -0.1100 \\
Jun & 149.2460 & 0.2505 & 0.0001 & -0.8415 & -0.1600 \\
Jul & 30.0591 & 0.9744 & 0.0107 & 1.6673 & 0.0186 \\
Aug & 102.8181 & 0.3733 & 0.0090 & 0.6862 & -0.0867 \\
Sep & 94.6386 & 0.8336 & 0.0062 & 0.3282 & -0.1300 \\
Oct & 150.4375 & -0.4354 & 0.0038 & -0.8060 & -0.1176 \\
Nov & 309.8648 & -3.6607 & -0.0108 & -5.8644 & -0.1480 \\
Dec & 13.2985 & 1.3349 & 0.0075 & 4.9952 & 0.0670 \\
Year & 142.1748 & -0.3757 & 0.0008 & -0.4147 & -0.0853 \\
\hline
\end{tabular}

\section{Data sources}

Radiation data, geographic latitude, altitude, vapor pressure, and sunshine hours were obtained from the China National Meteorological Information Center. The data of the center was handed by the "Monthly Meteorological Record Monthly Data Report" published by climate data processing departments of Chinese provinces, municipalities and autonomous regions. All data has undergone rigorous quality control and inspection, and the data quality is guaranteed.

There are two meteorological observation stations in Chongqing city, one of which is Chongqing Station and the other is Shapingba station. The two stations are only $10 \mathrm{~km}$ apart, and the different in meteorological conditions is extremely small, so the geographical influence can be ignored. The data of Chongqing station are from 1958 to 1986, and the data of Shapingba station are from 1987 to present. In this paper, the solar radiation annual value, monthly value, sunshine hours, geographical latitude, altitude and average absolute humidity in Chongqing from 1961 to 2012 are come from the two meteorological observation stations and selected as the basic data for the study. All data were quality controlled using quality control methods, including climate limit value or 
allowance value check, internal consistency check, time continuity check and time series consistency check.

\section{Conversion of annual total illuminance data}

The annual or monthly luminous efficacy value of Chongqing under different climate conditions $\left(K_{\mathrm{G} i}\right)$ can be obtained with Equation 1. Combined with the annual or monthly total irradiance value $\left(E_{\mathrm{e}}\right)$ in the region, annual or monthly total illuminance data $\left(E_{\mathrm{v}}\right)$ in this region can be calculated with Equation 2. The distribution of total illuminance values in Chongqing is shown in Figures 1 and 4.

$$
E_{\mathrm{v}}=K_{\mathrm{Gi}} E_{\mathrm{e}}
$$

\section{Research methods}

\section{Mann-Kendal trend analysis}

We suppose that time series $\left(x_{1}, x_{2}, \ldots, x_{n}\right)$ has no trend. Statistics $S$ is calculated through the following calculation method (Eq. 3).

$$
S=\sum_{k=1}^{n-1} \sum_{j=k+1}^{n} \operatorname{sgn}\left(x_{j}-x_{k}\right)
$$

where $S$ has a normal distribution, a mean value of 0 , and variance of $\operatorname{var}(S)=\frac{n(n-1)(2 n+5)}{18}$. The standard calculation method for normal statistics is provided below (Eq. 4):

$$
Z= \begin{cases}\frac{S-1}{\sqrt{\operatorname{var}(S)}} & S>0 \\ 0 & S=0 \\ \frac{S+1}{\sqrt{\operatorname{var}(S)}} & S<0\end{cases}
$$

For a given confidence level $\alpha$ in the bilateral trend test, we suppose that the null hypothesis is unacceptable if $|Z| \geq Z_{1-\alpha / 2}$. The time series data exhibit an obvious increasing or decreasing trend at a confidence level of $\alpha$.

Based on the trend test, Sen's method is insignificantly affected by missing data errors or outliers. Using Sen slope calculate $Q^{\prime}$, if $Q^{\prime}$ is a positive number, indicating that the data has a growing trend; if $Q^{\prime}$ is a negative number, indicating that the data has a downward trend. We can obtain the slope estimate $Q^{\prime}$ by using Equation 5:

$$
Q^{\prime}=\operatorname{median}\left(\frac{x_{i}-x_{j}}{i-j}\right) \quad \forall j<i
$$

where $1<j<i<n$; median represents the median function. 


\section{Mann-Kendall mutation test}

We suppose that time series $\left(x_{1}, x_{2}, \ldots, x_{n}\right)$ exists. One order series, $m_{i}$ (Kendall, 1975), is constructed to represent the sample accumulative number of $x_{i}>x_{j}(1<j<i) . d_{k}$ is defined as (Eq. 6)

$$
d_{k}=\sum_{i=1}^{k} m_{i} \quad 2 \leq k \leq n
$$

The mean value and variance of $d_{k}$ can be approximately expressed as (Eqs. 7 and 8)

$$
\begin{gathered}
E\left(d_{k}\right)=\frac{k(k-1)}{4} \\
\operatorname{var}\left(d_{k}\right)=\frac{n(n-1)(2 n+5)}{72} \quad 2 \leq k \leq n
\end{gathered}
$$

Under the hypothesis that the time series is random and independent, the statistics is defined as (Eq. 9)

$$
\mathrm{UF}_{k}=\frac{d_{k}-E\left(d_{k}\right)}{\operatorname{var}\left(d_{k}\right)} \quad k=1,2, \ldots, n
$$

Given the significance level of $\alpha,\left|\mathrm{UF}_{k}\right|>\mathrm{UF}_{\alpha / 2}$ means that the series has an obvious change trend. Tine series $x_{i}$ is arranged in a reverse order and calculated it with Equation 7 while ensuring that (Eq. 10)

$$
\left\{\begin{array}{l}
\mathrm{UB}_{k}=-\mathrm{UF}_{k} \\
k=n+1-k
\end{array}\right.
$$

By analyzing statistical series $U F_{k}$ and $U B_{k}$, the change trend of series $x_{i}$ can be further analyzed and the mutation time and region can be determined. $U F k>0$ indicates that the series tends to increase; $U F_{k}<0$ indicates that the series tends to decrease. When the series exceed the credibility line, then they exhibit an obvious increasing or decreasing trend. If an intersection point exists between the curves of $U F_{k}$ and $U B_{k}$ and falls between the credibility lines, the corresponding time of the intersection point is the starting moment of mutation.

\section{Results}

\section{Change trend analysis of annual total illuminance}

Based on the series of annual total illuminance values in Chongqing from 1961 to 2010, the statistical values $\mathrm{Z}$ obtained through Mann-Kendall trend test method was 3.96. A positive $Z$ value represents an increasing trend, whereas a negative $Z$ value represents a decreasing trend. Absolute $Z$ values equal to or greater than 2.56 indicate that the values passed significance tests with confidence coefficients of $99 \%$. This shows that 
the change trend of the annual total illuminance in Chongqing is decreasing, and the change trend is very obvious. Therefore, the natural annual total illuminance value in Chongqing should be corrected by combining the change trend of the data.

According to the slope $\left(Q^{\prime}\right)$ value obtained from the Mann-Kendall trend test (Sen Slope) (Fig. 1), the natural annual total illuminance of Chongqing dropped by $2.4 \times 10^{8}$ lx/10a. According to the slope $Q$ ' value, compared with the standard value of the natural annual total illuminance in the mid-1980s, the natural annual total illuminance decreases by about $10 \%$. Using the original daylighting illuminance standard value to design will bring greater errors. Therefore, the annual total illuminance standard value of Chongqing should be revised to adapt to the current natural lighting design requirements under current climate conditions in Chongqing.

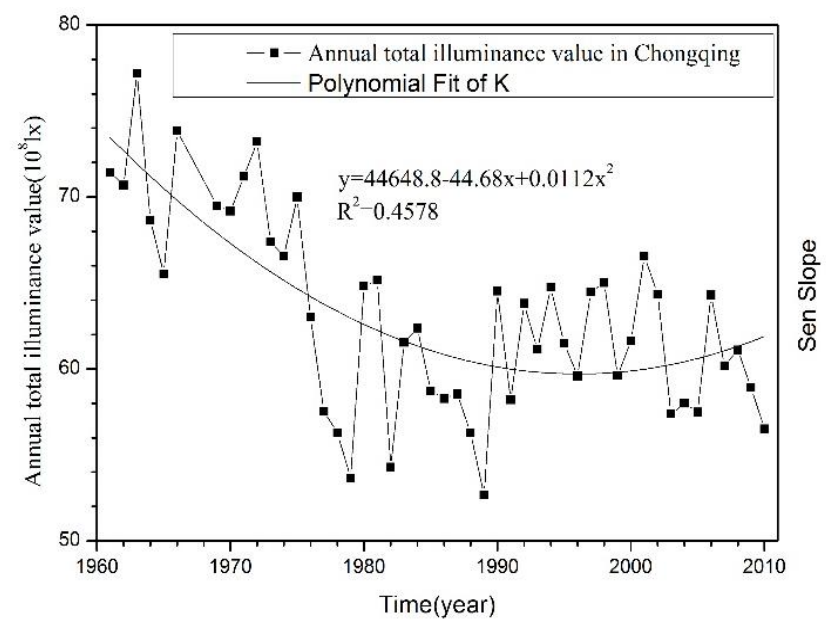

Figure 1. Changes of annual total illuminance value in Chongqing between 1961 and 2010

\section{Mutation analysis of annual total illuminance}

The annual total illuminance mutation map (shown in Fig. 2) of Chongqing was drawn through Mann-Kendall mutation test method. From Figure 2 we can see that the curves of $U F_{k}$ and $U B_{k}$ intersect in 1974, and the intersection point exists between and falls between the credibility lines, the corresponding time of the intersection point is the starting moment of mutation, so the Mutation occurred in 1974. Relevant research findings are also found in other cities in China (He et al., 2013). From Figure 2 we also find the forward sequence curve $\left(U F_{k}\right)$ is almost below 0 . It indicates that the series tends to decrease. The forward sequence curve $\left(U F_{k}\right)$ showed a rapid downward trend after 1974, and passed the 1.96 confidence level critical value. It shows that the decreasing trend became more obvious. After that, the absolute value of statistics in 1979 exceeded 3 , and even reached 4.65 in 1989. It shows that the annual total illuminance value of natural light in Chongqing has a very significant downward trend in recent years.

\section{The monthly illuminance distribution and change trend of Chongqing}

\section{Total illuminance distribution for each month}

Equation 1 is used to calculate the $K_{G i}$ values for each month of Chongqing from 1961 to 2012, and the monthly illuminance values of each year can be calculated according to Equation 2. Table 2 shows the average value of the total natural light intensity for each 
month from 1961 to 2012 (Figure 3a) and the average number of hours of sunshine in each month from 1961 to 2012 (Figure 3b).

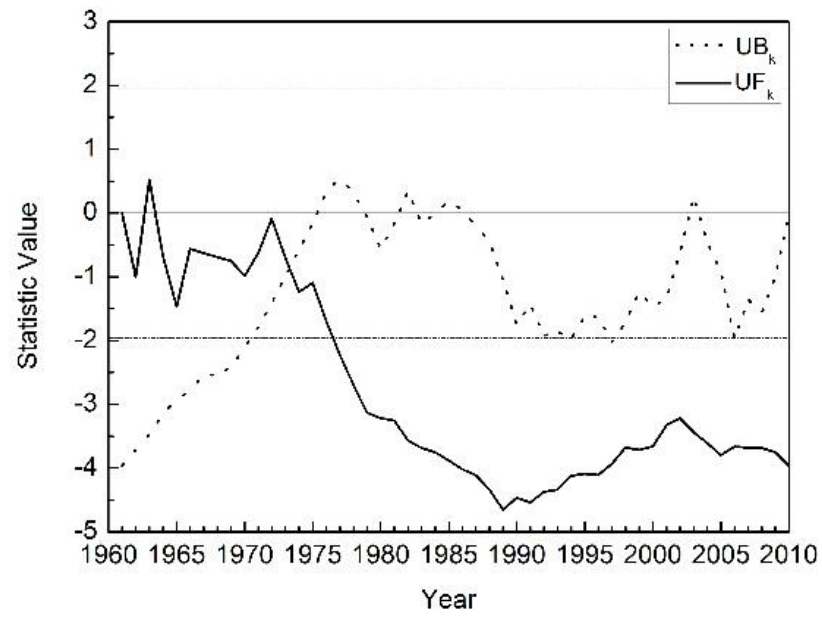

Figure 2. Mann-Kendall mutation detection of annual total illuminance value in Chongqing

Table 2. Average monthly total illuminance and monthly sunshine duration of natural light between 1961 and 2012

\begin{tabular}{c|c|c|c|c|c|c|c|c}
\hline Month & $\mathbf{1}$ & $\mathbf{2}$ & $\mathbf{3}$ & $\mathbf{4}$ & $\mathbf{5}$ & $\mathbf{6}$ & $\mathbf{7}$ & $\mathbf{8}$ \\
\hline Illuminance $/ \times 10^{8} \mathrm{~lx}$ & 2.01 & 2.82 & 4.66 & 6.32 & 7.04 & 7.05 & 9.19 & 9.53 \\
Daylight hours $/ \mathrm{h}$ & 27.4 & 35.8 & 74.3 & 103.9 & 111.7 & 108 & 178 & 193 \\
Month & 9 & 10 & 11 & 12 & Mean & Std. deviation & Min & Max \\
Illuminance $/ \times 10^{8} \mathrm{~lx}$ & 5.71 & 3.58 & 2.54 & 1.80 & 5.19 & 2.70 & 1.8 & 9.53 \\
Daylight hours $/ \mathrm{h}$ & 107.8 & 56.8 & 41.1 & 25.1 & 88.56 & 55.96 & 25.1 & 193 \\
\hline
\end{tabular}

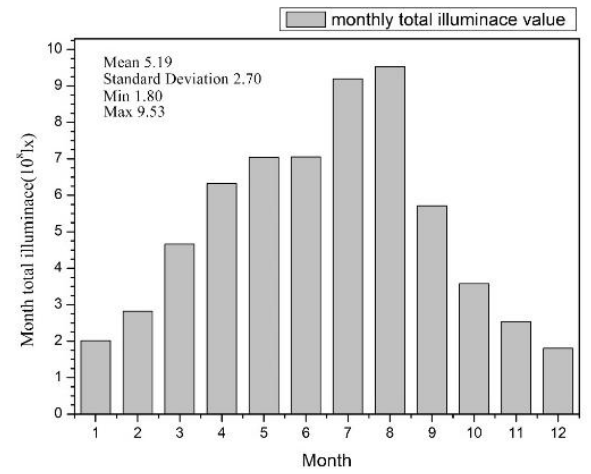

(a) Monthly total illuminance

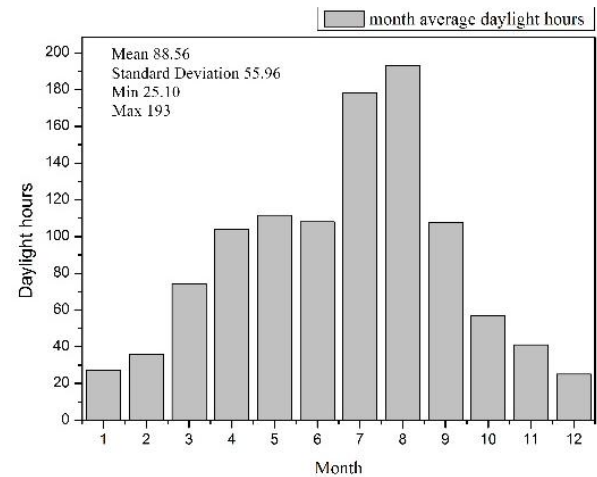

(b) Monthly sunshine duration

Figure 3. Average monthly total illuminance and monthly sunshine duration of natural light between 1961 and 2012

From Figure 3 we can see the change trend of the monthly total illuminance in Chongqing is similar to that of the corresponding monthly sunshine duration. The low values of the monthly total illuminance and sunshine duration are observed in 
December and in January. The high values are observed in July and in August. In addition, monthly total illuminance and monthly sunshine duration in summer is the largest; the minimum is in winter; and the middle is in spring and autumn. The total monthly illuminance and sunshine duration in spring are greater than those in autumn. The lowest value of total illumination in December was less than $1 / 5$ of the highest value of total illumination in August, and the average number of sunshine duration in December was even less than $1 / 7$ of the average number of duration of sunshine in August. This also shows that the monthly total illuminance in Chongqing varies with the seasons, with uneven distribution of total natural illuminance in each month. natural light is sufficient in Summer and scarce in winter.

Based on the above analysis, in accordance with the existing daylight design standards, daylighting can fully meet the needs of indoor illuminance, and may lead to the introduction of excessive natural light in summer, so we should pay attention to the orientation of the building windows and shade. In winter, the outdoor natural illumination is low, and due to the impact of climate change, the actual natural illuminance value is often lower than the standard value, which will lead to insufficient indoor illuminance, which will affect the use of building and cause energy waste. Therefore, the window area should be appropriately enlarged, or increase structural measures to increase the amount of natural light introduced into the room to meet the daylight needs.

\section{The change trend of monthly total illuminance}

The statistical values $Z$, Sen slope value $Q^{\prime}$, of monthly total illuminance were obtained through Mann-Kendall trend test method based on the series of monthly total illuminance values in Chongqing (Table 3).

Table 3. Monthly total illumination Mann-Kendall trend test statistics in Chongqing

\begin{tabular}{c|c|c|c|c|c|c|c|c|c|c|c|c}
\hline Month & $\mathbf{1}$ & $\mathbf{2}$ & $\mathbf{3}$ & $\mathbf{4}$ & $\mathbf{5}$ & $\mathbf{6}$ & $\mathbf{7}$ & $\mathbf{8}$ & $\mathbf{9}$ & $\mathbf{1 0}$ & $\mathbf{1 1}$ & $\mathbf{1 2}$ \\
\hline$Z$ & -3.07 & -1.77 & -1.446 & -1.738 & 0.405 & -2.19 & -2.87 & -2.57 & 0.698 & -1.79 & -0.731 & -3.25 \\
$Q^{\prime}$ & -0.011 & -0.012 & -0.012 & -0.017 & 0.006 & -0.024 & -0.038 & -0.033 & 0.009 & -0.015 & -0.004 & -0.015 \\
\hline
\end{tabular}

A positive $Z$ value represents an increasing trend, whereas a negative $Z$ value represents a decreasing trend. Absolute $Z$ values equal to or greater than $1.64,1.96$, and 2.56 indicate that the values passed significance tests with confidence coefficients of 90\%, 95\% and 99\%, respectively. Table 3 shows that in January, in July, in August and in December passed the significance test with a confidence coefficient of $99 \%$, indicating that the change trends in these months are very obvious. In February, in April and in October passed the significance test with a confidence coefficient of $95 \%$, indicating that the change trend in these months is obvious. In March passed the significance test with a confidence coefficient of $90 \%$, indicating that the change trend in the month is not obvious. In May, in September and in November failed to pass the significance test with a confidence coefficient of $90 \%$, which means that no change trend exists.

Slope value Q' represents monthly total illuminance change. A positive Q' value denotes an increasing trend, whereas a negative Q' value denotes a decreasing trend. 
Table 3 and Figure 4 show that only the monthly total illuminance changes exhibit positive values in May and in September, The other months exhibit a decreasing trend. The monthly total illuminance have large change in July and in August, the change values are $-0.38 \times 10^{8} \mathrm{~lx} / 10 \mathrm{a}$ and $-3.3 \times 10^{8} \mathrm{~lx} / 10 \mathrm{a}$. The monthly total illuminance have Minimum change in May and in November, the change values are $0.06 \times 10^{8} 1 \mathrm{x} / 10 \mathrm{a}$ and $-0.04 \times 10^{8} \mathrm{~lx} / 10 \mathrm{a}$. The variation trend of monthly total illuminance values in most months in Chongqing is consistent with the variation in annual total illuminance values, that is, the overall trend shows a downward trend. In January, in February, in October, in November, and in December in Chongqing, there are many overcast days, and the sunshine duration are low, therefore, the monthly total illuminance values in these months are stable. But in March, in April, in May, in June, in July, in August and in September, the climate change was relatively large, and the sunshine duration changed greatly. As a result, the monthly total illuminance values in these months were drastically changed.
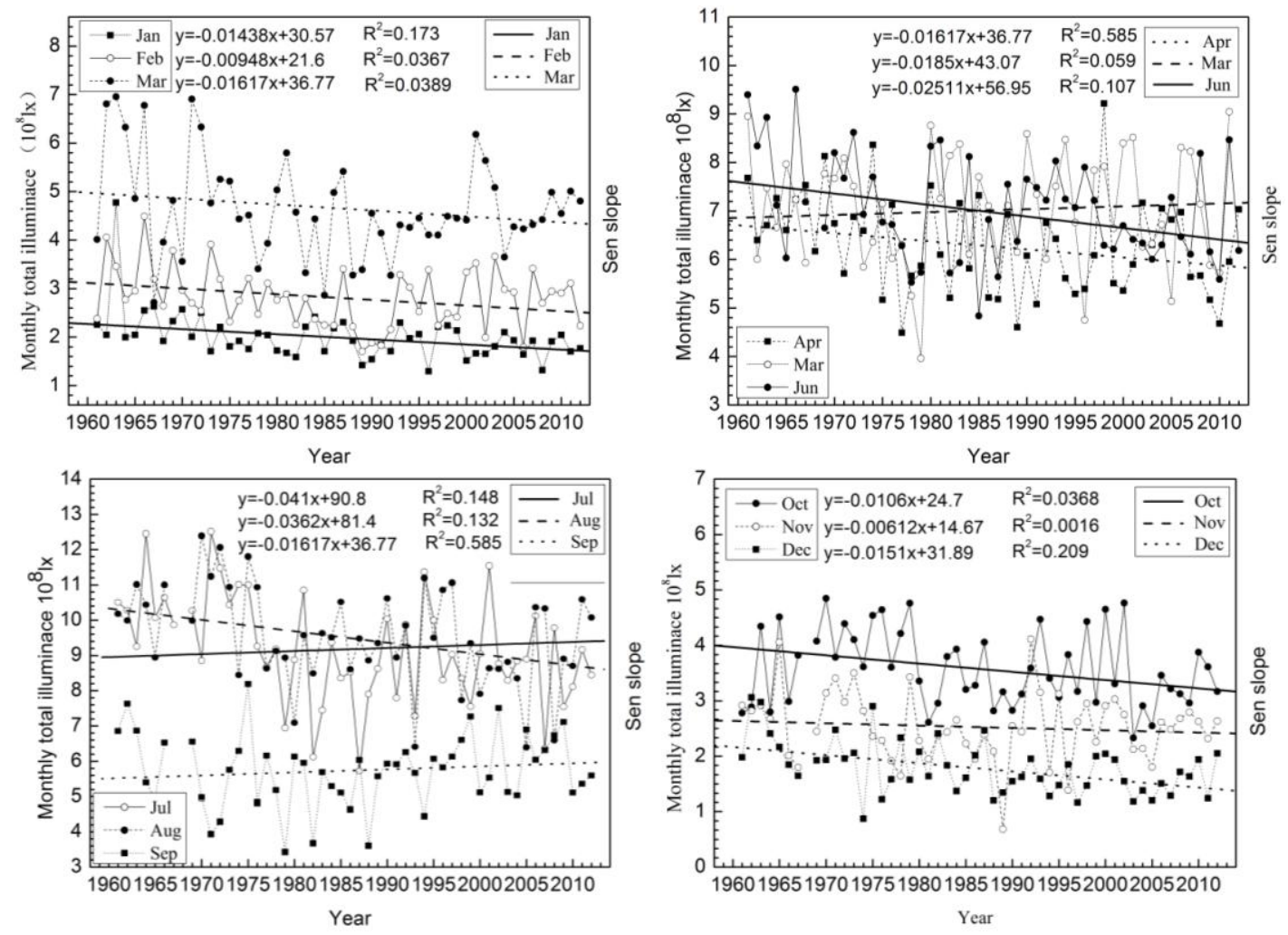

Figure 4. Variation trend of monthly total illuminance value in Chongqing between 1961 and 2012

\section{Discussion}

Natural light is the visible part of solar radiation; thus, the effects of solar radiation corresponding to meteorological factors also affect natural illumination changes. Solar radiation that reach the ground is influenced by clouds, atmosphere (including basic atmospheric composition, aerosols, and water vapor), and changes in solar radiation. We discuss the influencing factors of natural light illuminance in the following subsections. 


\section{Cloud}

Clouds have a significant impact on natural lighting climates. Clouds affect not only the natural light reaching the ground but also the sky luminance distribution. In general, changes in the cloud cover will lead to a decrease or increase in natural light.

\section{Aerosol}

Aerosol is another important and complex influencing factor of natural light. Aerosol not only reflects, scatters, or absorbs sunlight but also produces indirect effects by changing the microphysical nature of clouds. The effects of aerosols on sunlight vary. An increase in aerosol content increases atmospheric optical thickness, thus correspondingly reducing the natural illumination that reaches the surface.

\section{Water vapor}

Water vapor absorbs sunlight. Research indicates that the global average of columnar water vapor content is $25 \mathrm{~mm}$. For every $1 \%$ increase in solar radiation, water vapor content increases from $3 \mathrm{~mm}$ to $6 \mathrm{~mm}$ (Ramanathan and Vogelmann, 1997). Water vapor changes will have insignificant effects on natural illumination.

\section{Atmospheric molecular scattering and absorption}

Atmospheric gas molecules also scatter and absorb sunlight. However, human activity has changed atmospheric gas composition in recent decades (such as $\mathrm{CO}_{2}$ ). Given that gas composition has low levels of ingredients in the atmosphere, the effect of atmospheric gas on natural illumination can be neglected.

\section{Solar activity}

Solar activity changes are mainly observed by satellite. To date, four independent space-based instruments directly observe total solar irradiance (Fröhlich, 2004). Solar radiation is typically an 11-year cycle and the amount of change is usually small and not more than $1 \%$ (Hamed, 2009). Therefore, the effect of solar activity can be ignored.

\section{Conclusion}

- Using solar radiation data to obtain natural illuminance data can greatly enrich daylighting climate data.

- The trend of total illuminance value of natural light in Chongqing is very obvious, with a drop of $2.4 \times 10^{8} \mathrm{~lx} / 10 \mathrm{a}$, and the mutation occurred in 1974 . Therefore, the design standard of daylighting in Chongqing should be revised to meet the needs of daylighting demand.

- Monthly total illuminance values in Chongqing have no change trend in May, in September, in November, very obvious decreasing trend in January, in July, in August and in December, obviously in February, in April and in October, and not obvious in March.

- The annual variation of the total monthly illuminance of natural light fluctuates little in January, in February, in October, in November, and in December, and fluctuates widely in March, in April, in May, in June, in July, in August, and in September. 
Acknowledgements. This work was financially supported by the National Natural Science Foundation of China (Grant No. 51878089), Chongqing Research Program of Basic Research and Frontier Technology (Grant No. cstc 2015jcyjBX0121).

\section{REFERENCES}

[1] Alpert, P., Kishcha, P., Kaufman, Y. J. et al. (2005): Global dimming or local dimming: effect of urbanization on sunlight availability. - Geophysical Research Letters 32: L17802.

[2] Fröhlich, C., Lean, J. (2004): Solar radiative output and its variability: evidence and mechanisms. - Astron and Astrophys Rev 12: 273-320. DOI: 10.1007 /s00159-0040024-1.

[3] Hamed, K. H. (2009): : Exact distribution of the Mann-Kendall trend test statistic for persistent data. - Hydrology 1: 86-94.

[4] He, Y., Mao, H., Quan, L. (2012): Sky luminance distribution types in China. - Journal of Central South University of Technology 3: 777-782.

[5] He et al. (2013): The trend of natural illuminance levels in 14 Chinese cities in the past 50 years. Energy, - Sustainability and Society 3: 22.

[6] Kendall, M. (1975): Multivariate Analysis. - Charles Griffin \& Company, London.

[7] Luo, T., Yan, D., Lin, R. et al. (2011): Study and application on the typical yearly daylight illuminance. - China Illuminating Engineering Journal 5: 1-6 [in Chinese].

[8] McBean, E., Motiee, H. (2008): Assessment of impact of climate change on water resources: along term analysis of the Great Lakes of North America. - Hydrol Earth Syst Sci 12: 239-255.

[9] Muneer, T., Gul, I. (1998): Long-term Evaluation of a Meteorological Solar Radiation Model against UK data. - Energy Conversion and Management 3/4: 303-317.

[10] Perez, R., Chen, I., Seals, R. (1990): Modeling daylight availability and irradiance components from direct and global irradiance. - Solar Energy 5: 271-289.

[11] Ramanathan, V., Vogelmann, A. M. (1997): Greenhouse effect, atmospheric solar absorption and the Earths radiation budget: from the Arrhenius-Langley era to the 1990s. - Ambio 26: 38-46.

[12] Shen, W. (2010): Trend analysis of precipitation in northern Xinjiang during 1953-2008. - Journal of Water Resources \& Water Engineering 4: 130-134 [in Chinese].

[13] Shen, Y., Zhao, Z., Shi, G. (2008): The Progress in variation of surface solar radiation, factors and probable climate effects. - Advances in Earth Science 9: 915-923 [in Chinese].

[14] Streets, D. G., Yu, C., Wu, Y. et al. (2008): Aerosol trends over China, 1980-2000. Atmospheric Research 2: 174-182 [in Chinese].

[15] Wand, Z., Han, L., Chen, X., et al. (2012): Characteristics and sources of $\mathrm{PM}_{2.5}$ in typical atmospheric pollution episodes in Beijing. - Journal of Safety and Environment 5: 122126 [in Chinese].

[16] Wang, A., Jin, H., Wang, H. et al. (2011): Obtaining outdoor illuminance values with solar irradiation transformation models. - Journal of Civil, Architectural \& Environmental Engineering 3: 88-93 [in Chinese].

[17] Wu, Q. (1987a): The light equivalent of total solar radiation and its application in the calculation of illumination climate. - Acta Meteorologica Sinica 5: 290-296 [in Chinese].

[18] Wu, Q. (1987b): The temporal and spatial distribution of total illumination in China. Acta Energiae Solaris Sinica 4: 347-351 [in Chinese].

[19] Zhang, Q., Li, Y., Chen, Q. et al. (2011): Temporal and spatial distributions of cloud cover over southwest China in recent 46 years. - Plateau Meteorology 2: 339-348 [in Chinese]. 